\title{
SIMPLE MAXIMUM POWER POINT CONTROLLER FOR SINGLE-PHASE GRID-CONNECTED PV SYSTEM
}

\author{
Ahmed A. A. Hafez \\ Electrical Engineering Department, Faculty of Engineering University \\ of Assiut, Assiut, PO 71516 Egypt
}

\section{Daniel Montesinos-Miracle and Antoni Sudrià-Andreu}

Centre d'Innovació Tecnològica en Convertidors Estàtics Accionaments (CITCEA-UPC), Departament d'Enginyeria Elèctrica Universitat Politècnica de Catalunya.ETS d'Enginyeria Industrial de Barcelona, Av. Diagonal, 647, Pl. 2. 08028 Barcelona, Spain

\section{(Received October 11, 2010 Accepted December 23, 2010)}

\begin{abstract}
This paper proposes a simple and efficient PI controller for single-phase grid-connected PV generator. The controller ensures the system operation at maximum power point (MPP) irrespective to atmospheric conditions. A detailed design of the controller and DC capacitor were carried out. An average-value model was developed to facilitate the design of the controller and to study the system performance under different operation conditions. The results were validated by rigorous simulation.
\end{abstract}

\section{INTRODUCTION}

The Photovoltaic (PV) power generation systems are renewable energy sources that expected to play a promising role in fulfilling the future electricity requirements [1-3]. Energy independence and environmental compatibility are two attractive features of PV systems. The fuel is free, and no noise or pollution is created from operating PV systems.

The PV systems principally classified into stand-alone, grid-connected or hybrid systems. The grid-connected PV systems generally shape the grid current to follow a predetermined sinusoidal reference using hysteresis-band current controller [4-5], which has the advantages of inherent peak current limiting and fast dynamic performance. However, the hysteresis controller employs variable switching frequency. The value of the switching frequency varies from maximum value near zero cross to a minimal near the peak of the waveform. Such modulation strategy produces random and unpredictable harmonics, which are not only pulse-width modulated but frequency-modulated as well. That pattern has the disadvantages of stressing the power switching devices, and producing undefined frequency spectrum, which complicates the design of the filters [4-5].

For best utilization, PV systems have to operate at their maximum power point (MPP). However, the MPP varies with the insolation, temperature and other ageing effects. Numerous MPP Tracking (MPPT) techniques were reported in the literature [614]. The methods vary in complexity, cost, sensors required, convergence speed, range of effectiveness, availability, and implementation hardware. In general, the MPPT 
continuously adjusts the solar array terminal voltage/current, such that the array delivers maximum power at different climatological and environmental conditions.

A simple and efficient MPPT is given in [12-13]. This technique emerged from the approximately linear relationship between the PV module short circuit and maximum power point currents at different climatological conditions. The current at maximum power is claimed in [12-13] to vary from 0.78 to 0.92 times the short-circuit current. The module short circuit current is determined either by direct measuring or sensing the solar irradiation levels using look-up table method [12].

This paper proposes simple and efficient single-phase grid-connected PV generator. A simple proportional-integral (PI) controller is proposed to ensure the system operation at MPP irrespective of atmospheric conditions. A detailed design of the controller and DC capacitor were carried out. An average model was developed to facilitate the design of the controller and to investigate the system performance under different operation conditions. The proposed system could be used for residential PV systems, due to the reduced cost.

\section{SYSTEM DESCRIPTION}

The proposed system consists of PV generator, single-phase H-bridge inverter, output filter, PI controller and grid as shown in Fig. 1. A low pass filter is used to reduce the ripples in the measured PV generator current.

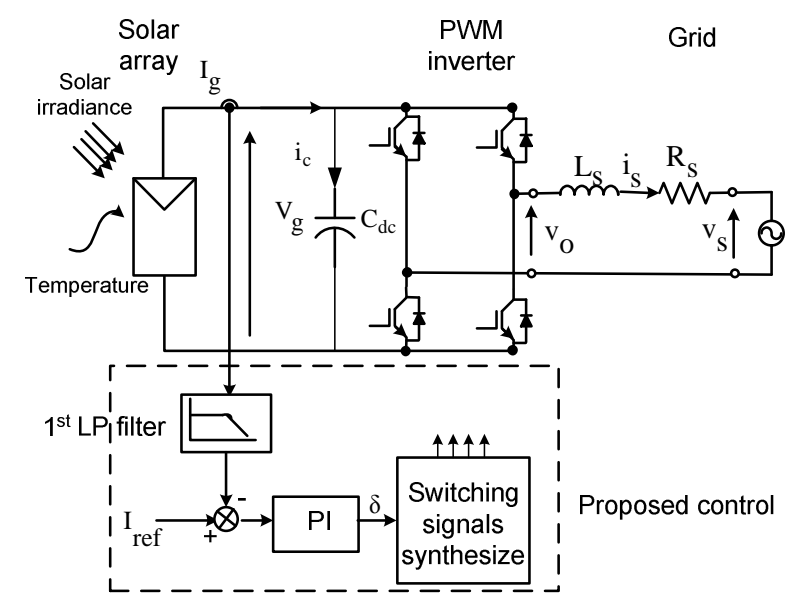

Fig. 1 The proposed single-phase grid-connected PV system

The terminal voltage of the PV generator Vg is related to line current Ig by,

$$
\mathrm{V}_{\mathrm{g}}=\mathrm{N}_{\mathrm{s}} \mathrm{V}_{\mathrm{t}} \ln \left(\frac{\mathrm{N} \mathrm{I} \mathrm{ph}_{\mathrm{p}}-\mathrm{I}_{\mathrm{p}}-\mathrm{N}^{\mathrm{O}}}{\mathrm{N}_{\mathrm{p}} \mathrm{O}}\right)
$$

where Vt, Iph, Io, Ns, NP are thermal voltage, photo current, diode saturation current, number of modules in series and in parallel respectively. The PV generator consists of 12 Kyocera KD210GX-LP modules. The parameters of the Kyocera KD210GX-LP module are given in Table1. 
TABLE I

Parameters of Kyocera KD210GX-LP [15]

\begin{tabular}{|l|c|}
\hline Temperature $\left({ }^{\mathbf{}} \mathbf{C}\right)$ & 25 \\
\hline Open circuit voltage (V) & 33.2 \\
\hline Short circuit current (A) & 8.58 \\
\hline Voltage at maximum power (V) & 26.60 \\
\hline Current at maximum power (A) & 7.9 \\
\hline Maximum power (W) & 210 \\
\hline
\end{tabular}

The powers of PV generator for different levels of solar irradiance at $25 \mathrm{oC}$ are calculated and shown in Fig. 2 as a function in the terminal voltage $\mathrm{Vg}$

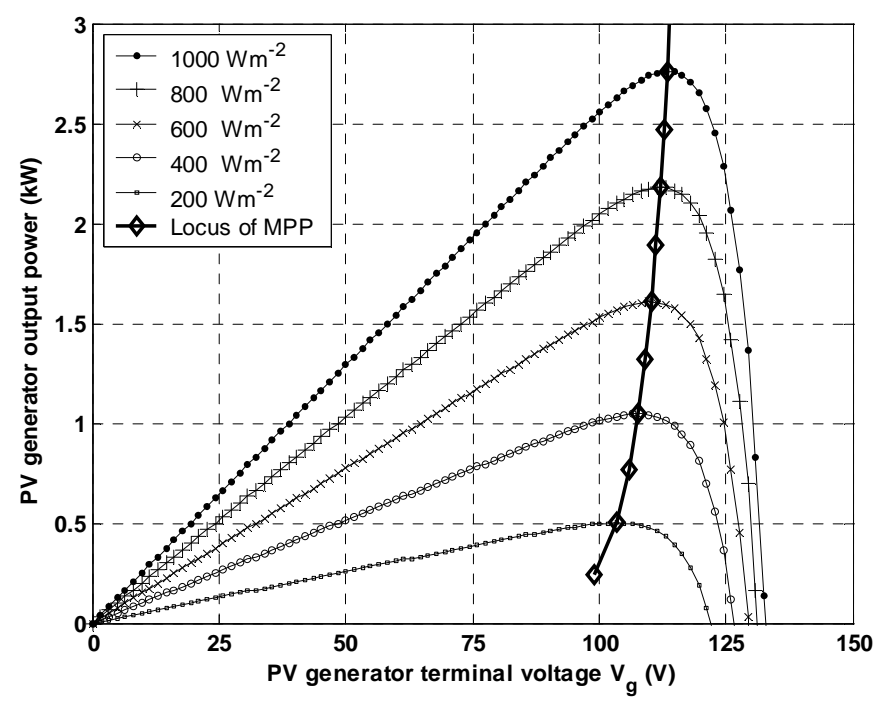

Fig. 2 PV generator power versus voltage at different solar irradiance levels and 25oC

Figure 2 shows that the variation of the solar irradiance has less impact on the voltage at MPP, as the voltage VMPP varies by $10 \%$ for $80 \%$ variation in the irradiation [12].

The proposed controller in Fig. 1 will continuously adjust the generator output current to track the reference. The reference current Iref represents the PV generator current at maximum power point.

The relation between the current Iref and phase shift $\delta$ can be derived by assuming that the system is lossless; therefore the power transferred to the grid equals the maximum generator output power Pgmax. $\delta$ is the angle between the grid voltage vs and the inverter output voltage vo

$$
\mathrm{P}_{\mathrm{gmax}}=\mathrm{I}_{\text {ref }} \mathrm{V}_{\mathrm{g}}=\frac{\left|\mathrm{v}_{\mathrm{o} 1}\right|\left|\mathrm{v}_{\mathrm{s}}\right|}{4 \pi \mathrm{L}_{\mathrm{S}}} \sin (\delta)
$$


The modulation strategy ensures that the amplitude of inverter fundamental output voltage $|\mathrm{Vo} 1|$ equals to the $\mathrm{PV}$ generator voltage $\mathrm{Vg}$, $|\mathrm{Vo} 1|=\mathrm{Vg}$; thus according to (2) the angle $\delta$ and hence grid power are controlled by the reference current Iref. Moreover, since Iref represents the PV generator current at maximum power point; therefore, the controller forces the system to always operate at MPP.

\section{AVERAGE-VALUE MODEL}

To facilitate the design of inverter and the controller, an average-value model of the system, Fig. 1, is obtained and given in Fig. 3.

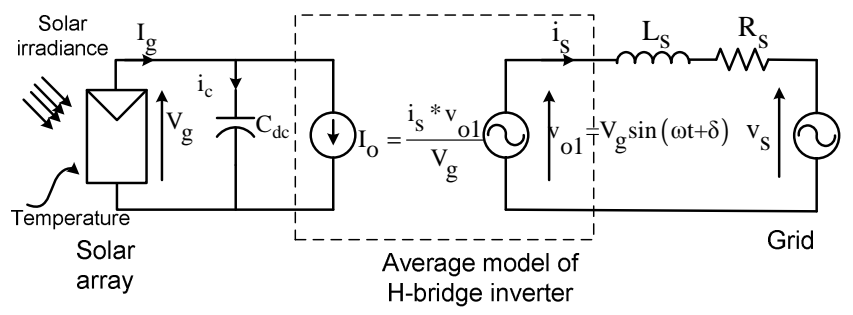

Fig. 3 Average model of single-phase grid-connected PV system

The average-value model of the PWM inverter is obtained by averaging the switching states of the inverter over a switching cycle, then averaging the resultant over the fundamental frequency cycle. Accordingly the inverter model can be expressed mathematically by,

$$
\begin{gathered}
\mathrm{L}_{\mathrm{S}} \frac{\mathrm{di}_{\mathrm{s}}}{\mathrm{dt}}=\left|\mathrm{V}_{\mathrm{g}}\right| \sin (\omega \mathrm{t}+\delta)-\left|\mathrm{V}_{\mathrm{S}}\right| \sin (\omega \mathrm{t})-\mathrm{i}_{\mathrm{S}} \mathrm{R}_{\mathrm{S}} \\
\mathrm{C}_{\mathrm{dc}} \frac{\mathrm{dV}_{\mathrm{g}}}{\mathrm{dt}}=\mathrm{I}_{\mathrm{g}}-\mathrm{i}_{\mathrm{S}} \sin (\omega \mathrm{t}+\delta)
\end{gathered}
$$

These equations are represented in Fig. 3 by the voltage source vo1 in the AC side, and the current source Io in the DC side. The input current of a single-phase inverter Io contains significant 2 nd harmonic ripple component. This is shown by equating the instantaneous inverter input and output powers and assuming sinusoidal inverter output voltage and current.

$$
\mathrm{I}_{\mathrm{O}}=\mathrm{i}_{\mathrm{S}} \sin (\omega \mathrm{t}+\delta)=\frac{\left|\mathrm{I}_{\mathrm{S}}\right|}{2}(\cos (\delta)-\cos (2 \omega \mathrm{t}+\delta))
$$

The low frequency current ripple component has to flow through the DC capacitor Cdc, otherwise it circulates in the PV generator producing significant power loss. Neglecting the capacitor parasitic resistance and switching ripples, the capacitor voltage ripple Vgpp is obtained by integrating the component in (5) at twice the grid frequency.

$$
\mathrm{V}_{\mathrm{gpp}}=\frac{1}{\mathrm{C}_{\mathrm{dc}}} \int \frac{\left|\mathrm{I}_{\mathrm{s}}\right|}{2} \cos \left(2 \omega \mathrm{t}+\delta-\frac{\pi}{2}\right) \mathrm{dt}=\frac{\left|\mathrm{I}_{\mathrm{s}}\right|}{4 \mathrm{C}_{\mathrm{dc}}{ }^{\omega}} \sin \left(2 \omega \mathrm{t}+\delta-\frac{\pi}{2}\right)
$$


The value of capacitor $C_{d c}$ can be obtained by,

$$
\mathrm{C}_{\mathrm{dc}}=\frac{\left|\mathrm{I}_{\mathrm{s}}\right|}{4 \xi \omega \mathrm{V}_{\mathrm{g}}}
$$

Where the ripple factor is given by $\xi=\mathrm{Vgpp} / \mathrm{Vg}$. The parameters of DC capacitor Cdc computed from (5)-(7) for the proposed system are given in Table 2.

\section{TABLE 2}

\section{Parameters of DC capacitor Cdc}

\begin{tabular}{|l|c|}
\hline Capacitor value(mF) & 20 \\
\hline Rated voltage (V) & 135 \\
\hline Rated current, RMS, (A) & 25.2 \\
\hline
\end{tabular}

\section{CONTROL DESIGN}

To operate the PV generator at MPP, a controller based on the fractional short-circuit current technique [10-11] is developed. As mentioned before that there is nearly a linear relation between short-circuit Isc and maximum power point IMPP currents in PV modules, Isc=kMPPIMPP. The gain kMPP is determined for Kyocera KD210GXLP from Fig. 4, where the short circuit Isc and maximum power point currents IMPP for different levels of temperature and irradiation are given.

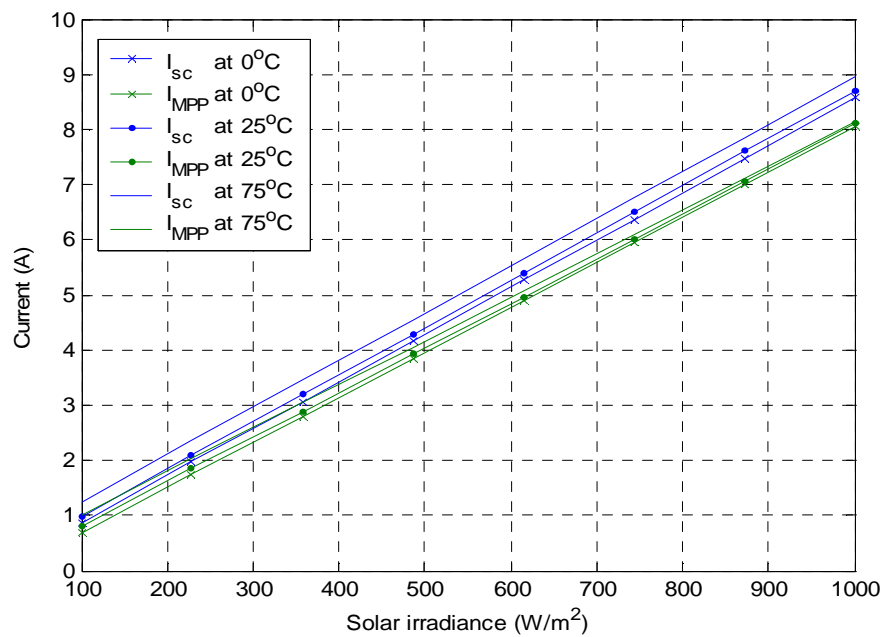

Fig .4 Short circuit Isc and maximum power point IMPP currents for different levels of solar irradiance at $0 \mathrm{oC}$ (crossed-line), $25 \mathrm{oC}$ (dotted-line) and $75 \mathrm{oC}$ (solid-line)

Figure 4 indicates that Isc is nearly linear related to IMPP. For Kyocera KD210GX-LP, IMPP can be approximately as 0.88Isc. This value is found to be a good comprise for different levels of solar irradiance and temperature. The value of short-circuit current Isc is determined through sensing the solar irradiation and temperature levels [12]. 
To facilitate the design of the controller, sufficiently high switching is assumed; therefore the grid line current could be considered nearly sinusoidal,

$$
\mathrm{i}_{\mathrm{S}}=\left|\mathrm{I}_{\mathrm{S}}\right| \sin (\omega \mathrm{t})
$$

Substituting (8) into (3)-(4) and ignoring the second harmonic components in the PV generator terminal voltage and inverter input current.

$$
\begin{gathered}
\mathrm{L}_{\mathrm{S}}\left|\mathrm{I}_{\mathrm{S}}\right| \cos (\omega \mathrm{t})+\mathrm{L}_{\mathrm{S}} \sin (\omega \mathrm{t}) \frac{\mathrm{d}\left|\mathrm{I}_{\mathrm{S}}\right|}{\mathrm{dt}}=\left|\mathrm{V}_{\mathrm{g}}\right| \sin (\omega \mathrm{t}) \cos (\delta) \\
+\left|\mathrm{V}_{\mathrm{g}}\right| \cos (\omega \mathrm{t}) \sin (\delta)-\left|\mathrm{V}_{\mathrm{S}}\right| \sin (\omega \mathrm{t})-\mathrm{R}_{\mathrm{S}}\left|\mathrm{I}_{\mathrm{S}}\right| \sin (\omega \mathrm{t}) \\
\mathrm{C}_{\mathrm{dc}} \frac{\mathrm{dV}_{\mathrm{g}}}{\mathrm{dt}}=\mathrm{I}_{\mathrm{g}}-\frac{\left|\mathrm{I}_{\mathrm{S}}\right|}{2} \cos (\delta)
\end{gathered}
$$
Rs in (9),

Separating the coefficients of $\sin (\omega t)$ and neglecting the drops in the resistor

$$
\mathrm{L}_{\mathrm{S}} \frac{\mathrm{d}\left|\mathrm{I}_{\mathrm{s}}\right|}{\mathrm{dt}}=\left|\mathrm{V}_{\mathrm{g}}\right| \cos (\delta)-\left|\mathrm{V}_{\mathrm{s}}\right|
$$

Considering a small disturbance around a steady-state operating point, the phase shift $\delta$ and the amplitudes of the PV generator terminal voltage $\mathrm{Vg}$, current Ig and grid current IIsI are all perturbed but the grid voltage/frequency are assumed constant;

$$
\begin{gathered}
\delta=\delta_{\mathrm{O}}+\Delta \delta \\
\left|\mathrm{I}_{\mathrm{S}}\right|=\left|\mathrm{I}_{\mathrm{so}}\right|+\Delta\left|\mathrm{I}_{\mathrm{s}}\right| \\
\mathrm{V}_{\mathrm{g}}=\mathrm{V}_{\mathrm{go}}+\Delta \mathrm{v}_{\mathrm{g}} \\
\mathrm{I}_{\mathrm{g}}=\mathrm{I}_{\mathrm{go}}+\Delta \mathrm{I}_{\mathrm{g}}
\end{gathered}
$$

The variables with capital letters and 'o' as subscript represent steady-state components while the ' $\Delta$ ' prefix denotes a small-signal component of a variable. It is assumed that the small-signal components are several orders of magnitude less than the respective steady-state values. Substituting (12)-(15) into (1), (10) and (11) and multiplying out, neglecting products of small-signal terms, then applying Laplace Transform, the small-signal model of the system is given by,

$$
\begin{aligned}
& \mathrm{sC}_{\mathrm{dc}} \Delta \mathrm{v}_{\mathrm{g}}=\Delta \mathrm{I}_{\mathrm{g}}-\frac{\Delta\left|\mathrm{I}_{\mathrm{s}}\right|}{2} \cos \left(\delta_{\mathrm{o}}\right)+\frac{\left|\mathrm{I}_{\mathrm{so}}\right|}{2} \sin \left(\delta_{\mathrm{o}}\right) \Delta \delta \\
& \mathrm{sL}_{\mathrm{s}} \Delta\left|\mathrm{I}_{\mathrm{s}}\right|_{\mathrm{s}}=\Delta \mathrm{v}_{\mathrm{g}} \cos \left(\delta_{\mathrm{o}}\right)-\mathrm{v}_{\mathrm{go}} \sin \left(\delta_{\mathrm{o}}\right) \Delta \delta-\mathrm{R}_{\mathrm{s}} \Delta\left|\mathrm{I}_{\mathrm{s}}\right| \\
& \Delta \mathrm{v}_{\mathrm{g}}=-\mathrm{k} \Delta \mathrm{I}_{\mathrm{g}}
\end{aligned}
$$

Solving (16)-(17), the open loop transfer function $\Delta \mathrm{Ig} / \Delta \delta$ can be given by, 


$$
\frac{\Delta \mathrm{I}_{\mathrm{g}}}{\Delta \delta}=\mathrm{G}_{\mathrm{g} \delta}=-\frac{\left|\mathrm{I}_{\mathrm{so}}\right| \sin \left(\delta_{\mathrm{o}}\right)\left(\mathrm{sL}_{\mathrm{s}}+\mathrm{R}_{\mathrm{s}}\right)+\mathrm{V}_{\mathrm{g}} \sin \left(\delta_{\mathrm{o}}\right) \cos \left(\delta_{\mathrm{o}}\right)}{\mathrm{s}^{2} \mathrm{kC}_{\mathrm{dc}} \mathrm{L}_{\mathrm{s}}+2\left(\mathrm{~L}_{\mathrm{s}}+\mathrm{kC}_{\mathrm{dc}} \mathrm{R}_{\mathrm{s}}\right) \mathrm{s}+\mathrm{k} \cos ^{2}\left(\delta_{\mathrm{o}}\right)+2 \mathrm{R}_{\mathrm{s}}}
$$

The frequency response of $\Delta \mathrm{Ig} / \Delta \delta$ is shown in Fig. 5 .

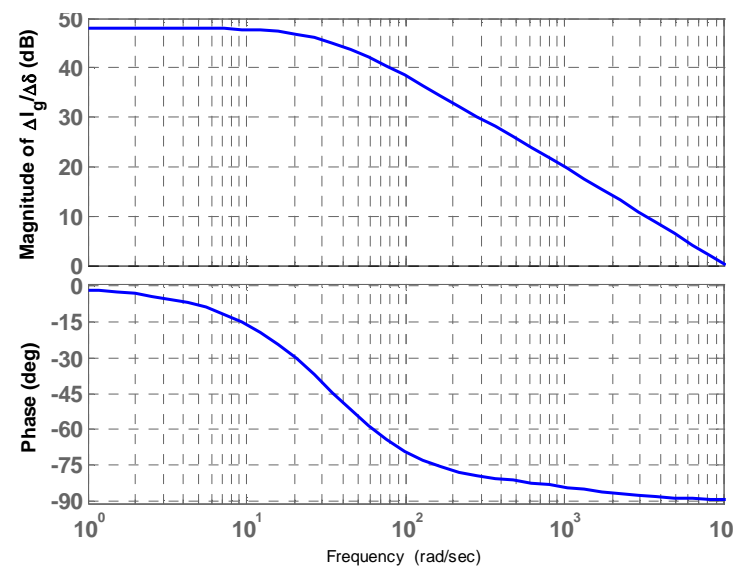

Fig. 5 Frequency response of $\Delta \mathrm{Ig} / \Delta \delta$

The open loop frequency response of $\mathrm{Gg} \delta$ is second order as shown in Fig. 4. This transfer function contains a low frequency pole and a high frequency pole. The system has $50 \mathrm{db}$ gain at low frequency and slope of $40 \mathrm{db} / \mathrm{rad} / \mathrm{sec}$ at high frequency.

As mentioned previously that controlling the PV generator current Ig controls the phase shift $\delta$ and hence output power; therefore the proposed controller for regulating the current Ig consists of PI controller as shown in Fig. 6.

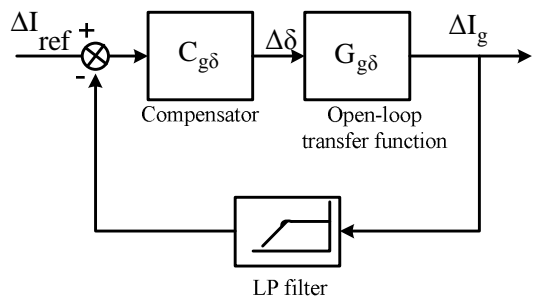

Fig. 6 Proposed PI controller

The cut-off frequency of the low pass filter, Fig. 6 , is set to $1 / 10$ of the second harmonic, this is to reduce the ripple in the control loop.

The zero of the PI controller, $\operatorname{Cg} \delta$, is set to cancel the low frequency pole in $\mathrm{Gg} \delta$, while the gain is to maintain the system stability and provide adequate bandwidth under different operating conditions. The parameters of the compensator $\mathrm{Cg} \delta$ are given in Table 3 for the proposed system.

TABLE 3

Parameters of compensator $\mathrm{Cg} \delta$

\begin{tabular}{|l|c|}
\hline Proportional gain kp & 0.4 \\
\hline Integral gain ki & 0.01 \\
\hline
\end{tabular}


Using the controller $\operatorname{Cg} \delta$, Table 3, the frequency response of the closed loop transfer function $\Delta \mathrm{Ig} / \Delta \mathrm{Iref}$ is given in Fig. 7.

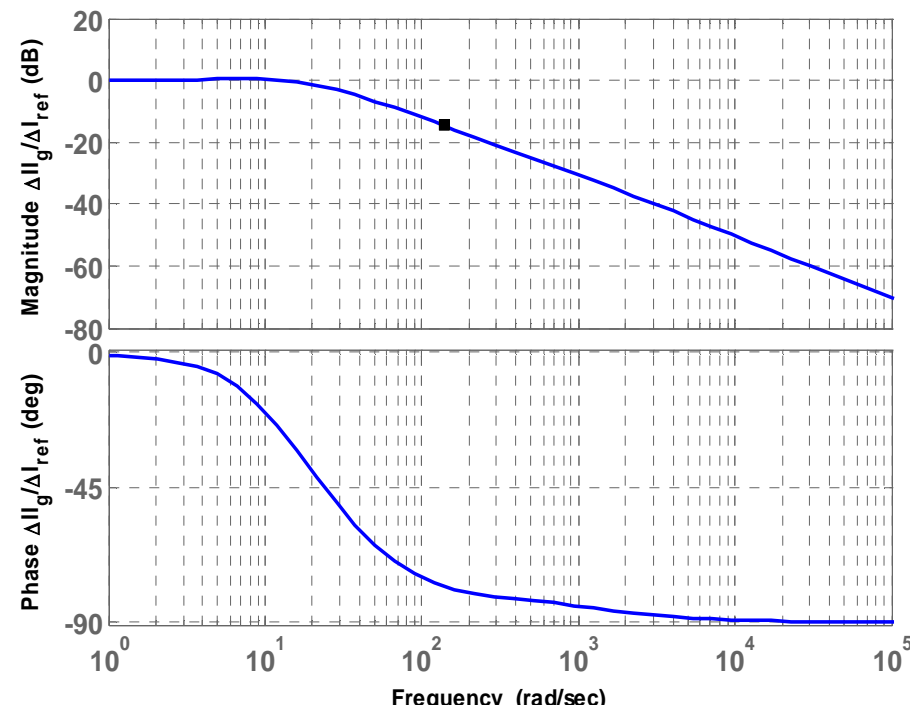

Fig. 7 Frequency response of closed loop transfer function $\Delta \mathrm{Ig} / \Delta \mathrm{Iref}$

Figure 7 shows that the controller in Table 3 resulted in bandwidth of around $50 \mathrm{rad} / \mathrm{sec}$. Increasing the bandwidth yields faster response, however, it results in significant ripple in the controlled signals. This deteriorates the grid current. Therefore the 50 rad/sec bandwidth is considered a good comprise between the performance speed and the attenuation of the low frequency ripple in the feedback signals.

\section{RESULTS AND DISCUSSION}

To validate the analysis, two programs in Micro-cap were developed, one simulate the full detailed model, Fig. 1, while the other simulates the average model with the controller, Fig. 3. In the detailed model the power switching devices are assumed ideal. The detailed model utilizes three-level PWM modulation strategy at $10 \mathrm{kHz}$ switching frequency. Therefore, the harmonics in the output voltage are predictable and centered around twice the switching frequency [16], which simplify their filtration. The results from these programs are compared in the following for different operating conditions. The parameters of the system, Fig. 1, used in the two programs are given in Table 4.

\section{TABLE 4}

Parameters of the proposed system, Fig. 1

\begin{tabular}{|l|c|}
\hline Value of output filter inductance (mH) & 3 \\
\hline Value of output filter resistance ( $\mathbf{\Omega})$ & 0.08 \\
\hline Grid voltage (RMS) (V) & 110 \\
\hline
\end{tabular}



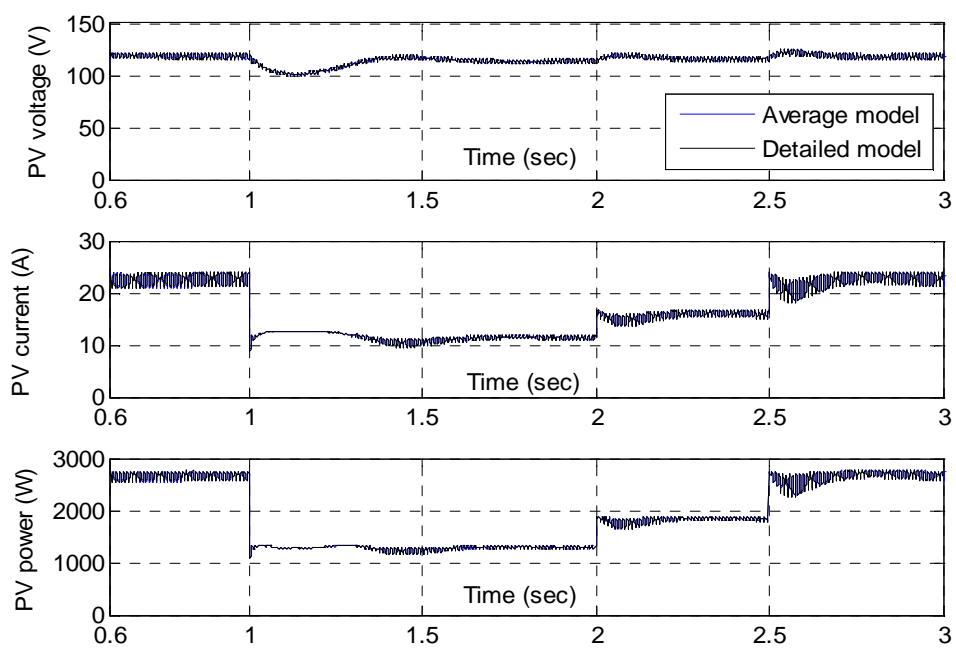

Fig. 8 PV voltage $\mathrm{Vg}$ (top), current Ig (middle) and power (bottom) for step change in the solar irradiance from $1000 \mathrm{Wm}-2$ to $500 \mathrm{Wm}-2$ at $1.0 \mathrm{sec}$ then from $500 \mathrm{Wm}-2$ to $700 \mathrm{Wm}-2$ at $2 \mathrm{sec}$ then from $700 \mathrm{Wm}-2$ to $1000 \mathrm{Wm}-2$ at $2.5 \mathrm{sec}$ from average model (blue) and detailed model (black) for temperature of $25 \mathrm{oC}$

The solar irradiance is stepped in different levels at 1,2 and $2.5 \mathrm{sec}$, Fig. 8, to ensure the robustness of the controller and its ability to instantaneously track the MPP irrespective to operating point/solar irradiation level.

A good agreement between the results from the detailed and average models is shown in Fig. 8. This demonstrates the advantages of average model as a simple, reliable and efficient tool in investigating the performance of single-phase PV gridconnected under different operating circumstances. Moreover, the simulation requirements regarding time and storage of the average model are significantly smaller compared with detailed model.

Figure 8 shows that the drop in the PV generator current, voltage and power for $50 \%$ reduction in solar irradiance are $50 \%, 6 \%$, and $50 \%$ respectively. The reduction in the current and power are attributed to the linear relation between the short circuit current and the solar irradiance [14]. The small reduction in the PV generator terminal voltage, $6 \%$, for $50 \%$ variation in the irradiation is expected as previously mentioned, Fig. 2.

Comparing Table 1 and Fig. 2 with Fig. 8 indicates that the proposed controller efficiently track the maximum PV generator power.

The ripples in waveforms in Fig. 8 are attributed to second harmonic current component in the inverter input current, equations (2) and (3).

Figure 8 show the PV terminal voltage experience around $6 \%$ deviation for $50 \%$ step transition in the solar irradiance, which is reasonable acceptable. 

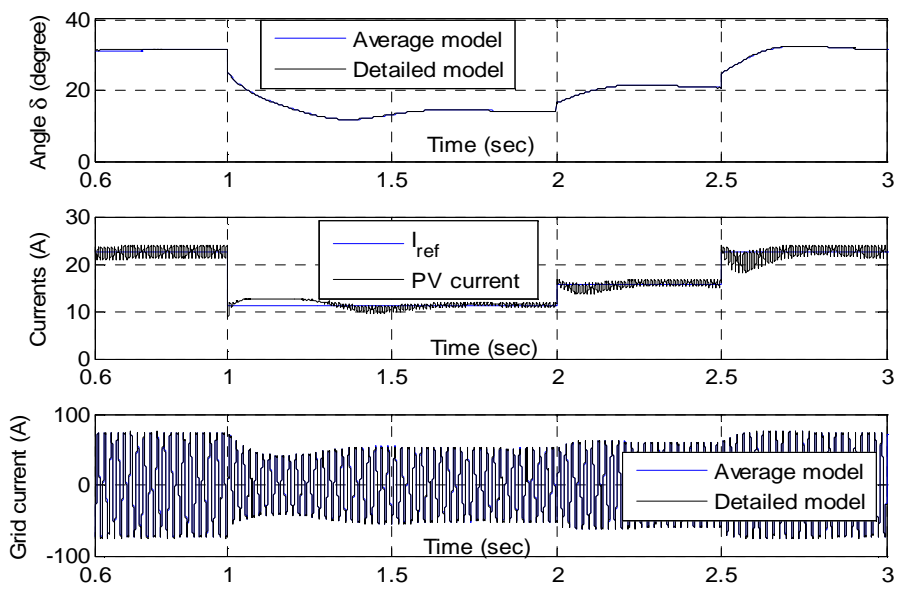

Fig. 9 Phase shift $\delta$ (top),reference and PV generator currents (middle) and grid current (bottom) for step change in the solar irradiance from $1000 \mathrm{Wm}-2$ to $500 \mathrm{Wm}-2$ at 1.0 sec then from $500 \mathrm{Wm}-2$ to $700 \mathrm{Wm}-2$ at $2 \mathrm{sec}$ then from $700 \mathrm{Wm}-2$ to $1000 \mathrm{Wm}-2$ at $2.5 \mathrm{sec}$ from average model (blue) and detailed model (black) for temperature of $25 \mathrm{oC}$

Figure 9 shows good agreement between the results of the switching model and the average model. The top graph in Fig. 9 corroborates the relation between the phase shift $\delta$ and the current at MPP IMPP that was identified in (2).

The proposed PI controller forces the PV generator current to track the IMPP during the steady-state and transient conditions, middle graph Fig. 9.

The bottom graph in Fig. 9 shows that the grid current is almost sinusoidal.
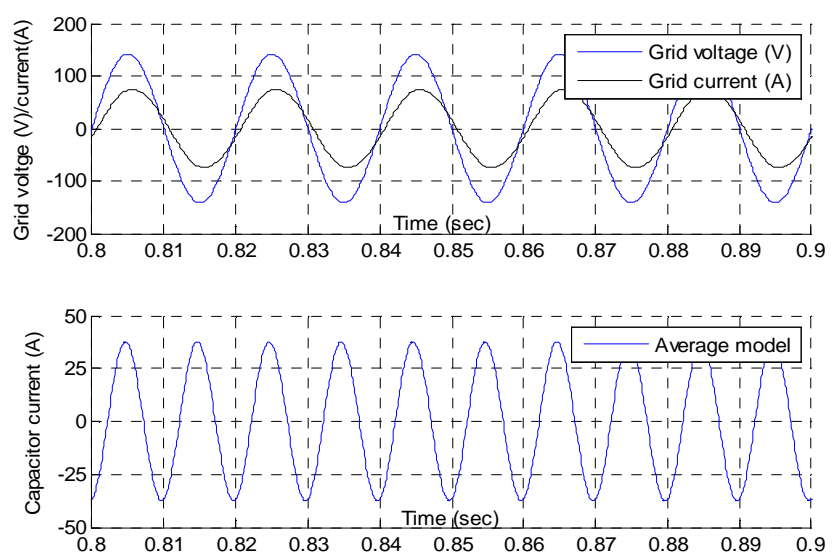

Fig. 10 Grid voltage and current (top) and average capacitor current (bottom) for solar irradiance of $1000 \mathrm{Wm}-2$ and $250 \mathrm{C}$ temperature

Again good correlation is shown between results from the switching and average models in Fig. 10. The modulation strategy used to synthesis the switching signals, has advantage of producing high quality grid current with THD less than $3 \%$. The grid voltage and current are almost in phase, top graph in Fig. 10, which validate the assumption mentioned previously in (8). 
The bottom graph in Fig. 10 shows that the current of Cdc capacitor pulsates twice the supply frequency. Moreover, the peak value of the current ic for solar irradiance of $1000 \mathrm{Wm}-2$ and $25 \mathrm{oC}$ temperature is $35.8 \mathrm{~A}$. This validates (5) and (7).

\section{CONCLUSION}

The following conclusions can be drawn:

1. In single-phase grid-connected PV system, a significant ripple current component at twice the grid frequency flows in the DC-link. This mandates the application of large DC capacitor, otherwise this component circulates between the PV generator and the inverter, which reduces the system efficiency and life cycle.

2. An average value model of the single-phase grid-connected PV system was developed. The average model predicts the steady-state and dynamic performance of system with reasonable accuracy as shown in the results. Moreover the average model requires less computation time and storage than the switching model. Therefore this model is considered as important tool in investigating the system performance under different operating conditions and in the designing of the controller.

3. The voltage at MPP could be considered to be less dependent on the solar irradiance

4. A simple PI controller was advised to allow the operation of the PV generator at MPP, while providing high quality grid current.

5. A good correlation between the results from the average value and full detailed model was shown in the results.

\section{ACKNOWLEDGMENT}

The authors are acknowledged for the Spanish Agency of International Development Cooperation (AECID) for funding this research work under project number A/20080/09.

\section{REFERENCES}

[1] J. T. Bialasiewicz, "Renewable Energy System with Photovoltaic Power Generators: Operation and Modeling," IEEE Transactions on industrial Electronics, vol. 55, p. 2752:2758, July 2008.

]2[ J. T. Bialasiewicz "Power-Electronics Systems for the Grid Integration of Renewable Energy Sources : A Survey " IEEE Transactions on industrial Electronics, vol. 53, p. 1002:1016, August 2006.

[3] E. Endo and K. Kurokawa, "Sizing procedure for photovoltaic systems "in IEEE First World Conference on Photovoltaic Energy Conversion, 1994., , 1994, pp. $1196-1199$.

[4] A. K. S. Bhat, S. B. Dewan" DC-to-Utility Interface Using Sine Wave Resonant Inverter" IEE proceedings, vol. 135, part B, No. 5, September 1988, pp. 193-201. 
[5] W. McMuarry, " Modulation of the chopping frequency in DC choppers and PWM inverters having current hysteresis controllers" IEEE Transaction Industry application, vol. IA-20, July/August 1984, pp. 763-768.

[6] H. R. Johan, Enslin;, S. Mario, Wolf;, B. S. Daniel, and S. Wernher, "Integrated Photovoltaic Maximum Power Point Tracking Converter " IEEE Transactions on industrial Electronics, vol ‘44 .pp. 769-773, December 1997.

[7] T. Esram, P. L. Chapman " Comparison of Photovoltiac Array Maximum Power Point Tracking Techniques" IEEE Transactions on Energy Conversion, vol. 22, 2007 .

[8] E. Roman, R. Alonso, P. Ibanez, S. Elorduizapatarietxe, D. Goitia, "Intelligent PV Module for Grid-Connected PV Systems," IEEE Transactions on industrial Electronics, vol. 53, pp. 1066-1073 ،June 2006.

[9] W. Yi-Bo;, W. Chun-Sheng;, L. Hua;, X. Hong-Hua;, and Page(s):, "Steady-state model and power flow analysis of grid-connected photovoltaic power system "in IEEE International Conference on Industrial Technology, 2008. ICIT 2008, pp.1- 6

[10] L. Yan Hong and D. C. Hamill, "Simple maximum power point tracker for photovoltaic arrays." vol. 36, 2000, pp. 1/2-2/2.

[11] H. Chhchiang and S. Chihming, "Study of Maximum Power Tracking Techniques and Control of DC/DC Converters for Photovoltaic Power System," IEEE Transactions on industrial Electronics, pp. 86-93, 1998.

[12] S. Yuvarajan, S. Xu" Photo-voltiac power converter with a simple maximumpower-point-tracker " Proceeding of 2003 International Symposium on Circuit and Systems 2003, pp. III-399-III-402

[13] J.-P. Lee;, B.-D. Min;, T.-J. Kim;, D.-W. Yoo;, and J.-Y. Yoo, "A Novel Topology for Photovoltaic DC/DC Full-Bridge Converter With Flat Efficiency Under Wide PV Module Voltage and Load Range "IEEE Transactions on ndustrial Electronics, vol. 55, pp. 2655 - 2663 July 2008.

[14] A. A. hafez, "simple and robust Maximum Power Point Tracking Algorithm for solar cell," in World Congress on Electronics and Electrical Engineering (WCEEENG'10), Luxor. Egypt, 4-8April 2010.

[15] Kyocera, http://www.kyocerasolar.com/products/pdf/specsheets/kd 210gxlp_081508, March, 2010

[16] N. Mohan, T. M. Undeland, and W. P. Robbins, "Power Electronics: Converters, Applications, and Design", 2nd edition. New York, Chichester, Wiley, 1995.
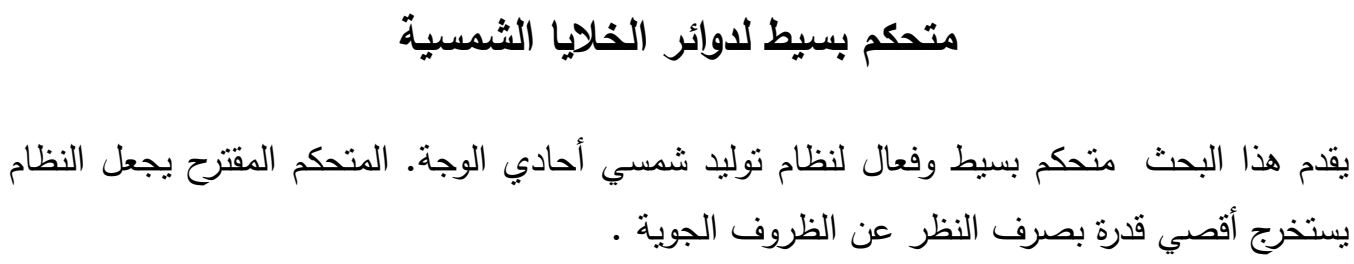